\title{
Discovery and Optimization of a Novel Triazole Series of GPR142 Agonists for the Treatment of Type 2 Diabetes
} \author{
Liangqin Guo, ${ }^{* \dagger}{ }^{\dagger}$ Dann L. Parker, ${ }^{\dagger}$ Yi Zang, ${ }^{\dagger}$ Ramzi F. Sweis, ${ }^{\dagger}$ Weiguo Liu, ${ }^{\dagger}$ Edward C. Sherer, ${ }^{\dagger}$
} Nicole Buist, ${ }^{\ddagger}$ Jenna Terebetski, Xiaofang Li, ${ }^{\S}$ Stan Mitelman, ${ }^{\S}$ Gino Salituro, ${ }^{\S}$ Maria E. Trujillo, "Michele Pachanski," Melissa Kirkland," Mary Ann Powles," George J. Eiermann," Yue Feng," Jin Shang," Andrew D. Howard," Feroze Ujjainwalla, ${ }^{\dagger}$ Christopher J. Sinz ${ }^{\dagger}$ John S. Debenham, ${ }^{\dagger}$ Scott D. Edmondson, ${ }^{\perp, \dagger}$ Ravi P. Nargund, ${ }^{\dagger}$ William K. Hagmann, ${ }^{\perp, \dagger}$ and Derun Li ${ }^{*}$,

$\dagger$ Departments of Medicinal Chemistry, ${ }^{\ddagger}$ Discovery Pharmaceutical Sciences, ${ }^{\S}$ Pharmacokenetics Pharmacodynamics Drug Metabolism, "Diabetes Research, and "Cardiometabolic Disease, Merck \& Co., Inc., MRL, 126 East Lincoln Avenue, PO Box 2000, Rahway, New Jersey 07065, United States

\section{Supporting Information}

ABSTRACT: GPR142 has been identified as a potential glucose-stimulated insulin secretion (GSIS) target for the treatment of type 2 diabetes mellitus (T2DM). A class of triazole GPR142 agonists was discovered through a high throughput screen. The lead compound 4 suffered from poor metabolic stability and poor solubility. Lead optimization strategies to improve potency, efficacy, metabolic stability, and solubility are described. This optimization led to compound

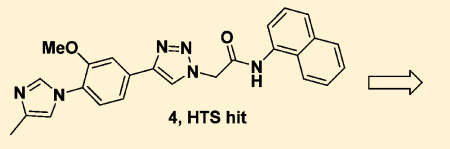

h-GPR142, IP, $E_{50}=252 \mathrm{nM}$ $\mathrm{m}-\mathrm{GPR} 142, I P, \mathrm{EC}_{50}=23 \mathrm{nM}$ mouse LM $32 \%$ remaining after $30 \mathrm{mins}$ Solubility at $\mathrm{pH} 2 / 7,40 \mu \mathrm{M} /<1 \mu \mathrm{M}$ $16 \%$ Glucose reduction in mOGTT @ $10 \mathrm{mpk}$

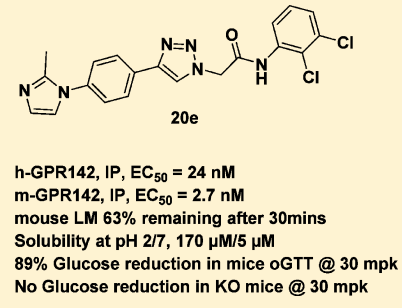

(1) Glucose reduction in mice OGTT @ $30 \mathrm{mpk}$ 20e, which showed significant reduction of glucose excursion in wild-type but not in GPR142 deficient mice in an oral glucose tolerance test (oGTT) study. These studies provide strong evidence that reduction of glucose excursion through treatment with 20e is GPR142-mediated, and GPR142 agonists could be used as a potential treatment for type 2 diabetes.

KEYWORDS: GPR142 agonists, type 2 diabetes mellitus (T2DM), triazole, glucose-stimulated insulin secretion (GSIS), solubility

$\mathrm{T}$ ype 2 diabetes mellitus (T2DM) is a disease derived from multiple causative factors and characterized by elevated levels of plasma glucose (hyperglycemia) in the fasting state or after administration of glucose during an oral glucose tolerance test (oGTT). ${ }^{1}$ Type 2 diabetic patients have increased risk of coronary heart disease, peripheral vascular disease, hypertension, nephropathy, and retinopathy. ${ }^{2}$ Therefore, safe and effective treatments of T2DM are highly desirable. Recently there has been a focus on the development of novel agents that promote glucose-stimulated insulin secretion (GSIS) from pancreatic $\beta$-cells, such as DPP-4 inhibitors, ${ }^{3}$ which could minimize the potential risk of hypoglycemia and other adverse effects associated with many current therapies. ${ }^{4}$

GPR 142 is a Gq-coupled, family A seven transmembrane Gprotein-coupled receptor (GPCR) that is highly expressed in pancreatic $\beta$-cells and has been identified as a potential GSIS target for the treatment of T2DM. ${ }^{5,6}$ Considerable interest is thus centered on the generation of potent and selective small molecule ligands as possible therapeutic agents for T2DM patients. ${ }^{7-11}$ For example, Yu et al. have reported the discovery of potent aminopyrazole-phenylalanine based GPR142 agonist 1 (Figure 1), which showed GPR142 dependent stimulation of insulin secretion in isolated mouse islets. ${ }^{9}$ Toda et al. reported GPR142 agonist 2, which showed potent glucose lowering

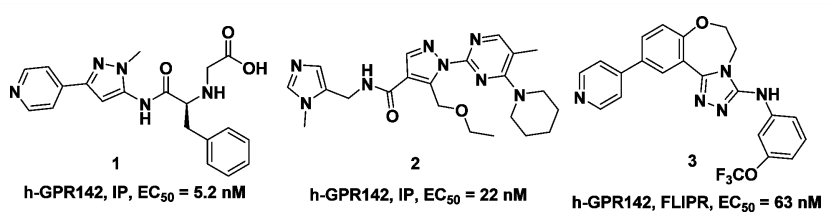

Figure 1. Examples of GPR142 agonists.

effects during an oral glucose tolerance test in mice and monkeys. ${ }^{10}$ More recently, Wilson et al. reported GPR142 agonist 3 (h-GPR142, FLIPR, $\mathrm{EC}_{50}=63 \mathrm{nM}$ ), which was active in oGTT study in wide type mice, but not in GPR142 deficient mice. $^{11}$

Herein, we report our hit-to-lead efforts in discovering novel, potent and orally bioavailable triazole GPR142 agonists and their pharmacological effects in mice. Triazole $\mathbf{4}$ was identified as a GPR142 agonist hit from a high throughput screen (HTS) (Figure 2). ${ }^{12}$ It exhibited modest human GPR142 agonist activity in a FLIPR assay (h-GPR142, FLIPR, $\mathrm{EC}_{50}=115 \mathrm{nM}$ ) and an inositol phosphate (IP) accumulation assay (h-GPR142,

Received: August 10, 2016

Accepted: October 6, 2016

Published: October 12, 2016 


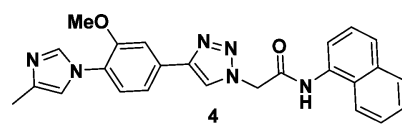

h-GPR142, FLIPR, EC ${ }_{50}=115 \mathrm{nM} \%$ remaining in h/r/m LM: 62/63/32 m-GPR142, FLIPR, EC ${ }_{50}=37 \mathrm{nM}$ Solubility in PBS: $40 \mu \mathrm{M}(\mathrm{pH}=2),<1 \mu \mathrm{M}(\mathrm{pH}=7)$ $\mathrm{h}$-GPR142, IP, $\mathrm{EC}_{50}=252 \mathrm{nM} \quad 16 \%$ Glucose reduction in mOGTT @ $10 \mathrm{mpk}$ m-GPR142, IP, EC $50=23 \mathrm{nM}$

Figure 2. Structure and profile of HTS hit 4.

IP, $\left.\mathrm{EC}_{50}=252 \mathrm{nM}\right) .^{13}$ Additionally, compound 4 had potent mouse GPR142 activity (m-GPR142, FLIPR, $\mathrm{EC}_{50}=37 \mathrm{nM}$; $\mathrm{m}$-GPR142, IP, $\left.\mathrm{EC}_{50}=23 \mathrm{nM}\right)$. Unfortunately, 4 only showed $16 \%$ reduction of glucose excursion at a $10 \mathrm{mg} / \mathrm{kg}$ oral dose in a mouse oral glucose tolerance test (oGTT). ${ }^{14}$ Given that $\mathbf{4}$ has relatively low mouse microsomal stability (32\% remaining after incubation for $30 \mathrm{~min}$ in mouse microsomes), and low solubility in phosphate buffer solution (PBS) at $\mathrm{pH}=2$ and 7 , a better tool compound for in vivo proof-of-concept studies was sought.

We first investigated whether the amide could be replaced by an amine, a reverse amide, or a urea linker (analogues 10a-10c, Table 1). The synthesis of $\mathbf{1 0 a}-\mathbf{1 0 c}$ started with alcohol 5

Table 1. SAR on the Amide and Naphthyl Replacements ${ }^{a}$

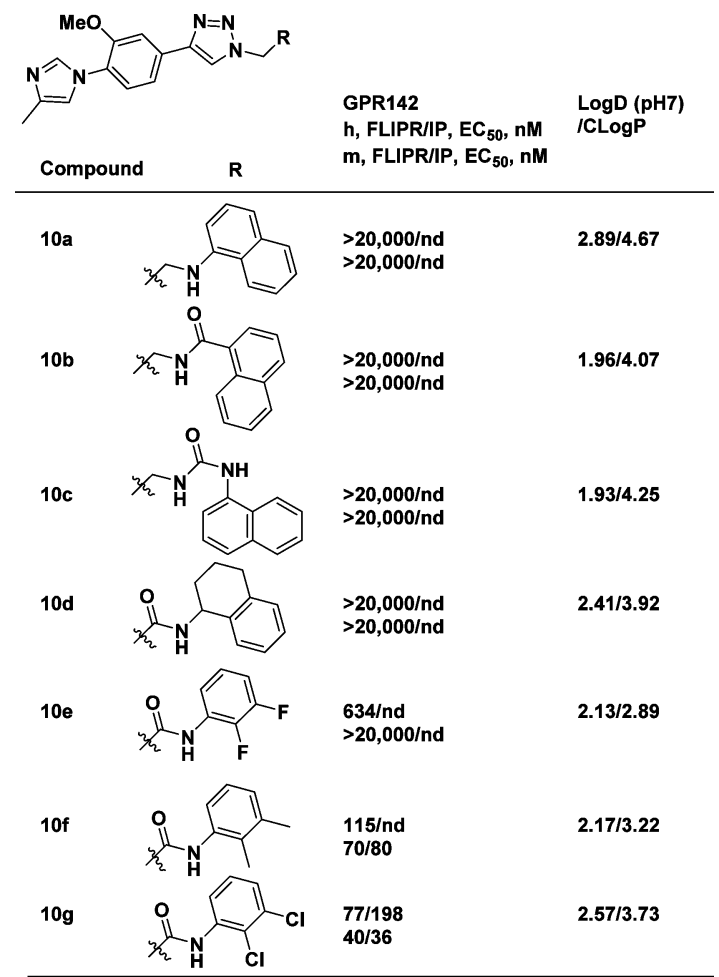

$a_{\mathrm{nd}}=$ not determined; assay protocols: see ref 15 .

(Scheme 1). Mesylation of $\mathbf{5}$ followed by azide displacement gave azide 6. A copper(I)-catalyzed azide-alkyne cycloaddition (CuAAC) reaction of azide 6 with known alkyne $7^{12}$ furnished triazole 8 in good yield. Deprotection of the Boc group of 8 afforded amine 9, which was subsequently converted to 10a$10 c$.

FLIPR assays were used to first assess GPR142 potency given their higher throughput. Potent compounds of interest from the FLIPR assay were then tested in GPR142 Inositol phosphate (IP) assays as secondary assays. ${ }^{13}$ Amine 10a, reverse amide 10b, and urea 10c lost GPR142 potency in the
Scheme 1. Synthesis of Triazole Analogues 10a-10 $\mathrm{c}^{a}$

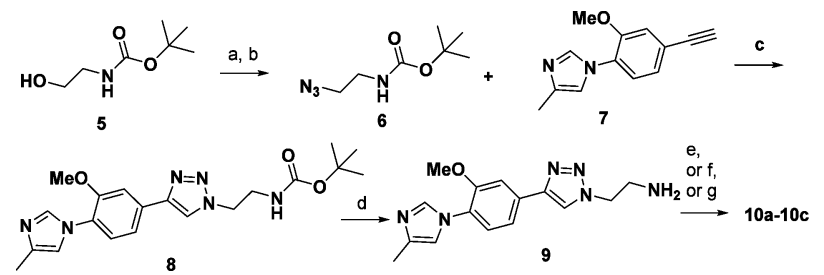

${ }^{a}$ Reagents and conditions: (a) $\mathrm{MsCl}, \mathrm{Et}_{3} \mathrm{~N}, \mathrm{DCM}$; (b) $\mathrm{NaN}_{3}, 15$ crown-5, DMF, $90{ }^{\circ} \mathrm{C}$; (c) $\mathrm{CuSO}_{4}$, sodium ascorbate, $t$ - $\mathrm{BuOH} / \mathrm{H}_{2} \mathrm{O}$; (d) $\mathrm{HCl}, \mathrm{DCM} / \mathrm{MeOH}$; (e) 1-bromonaphthalene, $\mathrm{NaOtBu}$, BrettPhos Pd G1, dioxane, $60^{\circ} \mathrm{C}$; (f) 1-isocyanatonaphthalene, $\mathrm{Et}_{3} \mathrm{~N}$, DCE; (g) 1-naphthoyl chloride, TEA, DCE.

FLIPR assay, suggesting that a rigid amide moiety was required for GPR142 potency.

We then set out to replace the flat naphthyl group (Table 1, 10d-10g) to improve the physicochemical properties of the current lead. The synthesis of $10 \mathrm{~d}-10 \mathrm{~g}$ was initiated with ethyl 2-bromoacetate 11 (Scheme 2). Azide displacement of the

Scheme 2. Synthesis of Triazole Amide Analogues $10 \mathrm{~d}-10 \mathrm{~g}^{a}$

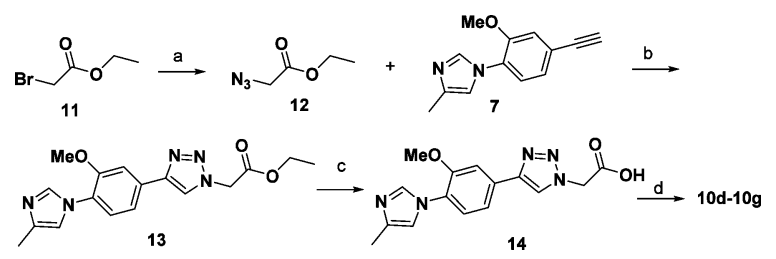

${ }^{a}$ Reagents and conditions: (a) $\mathrm{NaN}_{3}, 15$-crown-5, DMF, $90{ }^{\circ} \mathrm{C}$; (B) $\mathrm{CuSO}_{4}$, sodium ascorbate, $t-\mathrm{BuOH} / \mathrm{H}_{2} \mathrm{O}$; (c) $\mathrm{LiOH}, \mathrm{THF} / \mathrm{MeOH} /$ $\mathrm{H}_{2} \mathrm{O}$; (d) amine, HATU, DIEA, DMF.

bromide followed by the $\mathrm{CuAAC}$ reaction afforded triazole 13 . Ester hydrolysis of $\mathbf{1 3}$ gave acid 14. Amide coupling of amines with 14 gave the final analogues $10 \mathrm{~d}-10 \mathrm{~g}$. A very tight structure-activity relationship (SAR) was observed. The aliphatic tetrahydronaphthalene analogue 10d lost GPR142 activity. While 2,3-difluorophenyl analogue 10e was considerably less potent than 4, the more lipophilic analogues, 2,3dimethylphenyl $10 \mathrm{f}$ and 2,3-dichlorophenyl $10 \mathrm{~g}$, maintained GPR142 activity in both FLIPR and IP assays.

After we discovered that 2,3-dichlorophenyl could serve as a replacement for the naphthyl group, we explored the SAR on the middle phenyl ring, and the left-hand side imidazole ring (Table 2). The general synthesis of 20a-20f is shown in Scheme 3. Displacement of the 4-fluoro substituent of aryl aldehyde 16 with imidazole 15 afforded aldehyde 17 . Alkynylation of aldehyde 17 with the Bestmann-Ohira reagent afforded alkyne 18, which was reacted with azide 19 to give triazole products $\mathbf{2 0 a}-\mathbf{2 0 f}$. A similar route was used to prepare analogue $\mathbf{2 0 g}$.

As shown in Table 2, $\mathbf{1 0 g}$ demonstrated moderately low microsome stabilities across various species and poor solubility. Replacing OMe with F resulted in modestly improved potency and liver microsome stability (20a). However, 2-fluoro substitution $20 \mathrm{~b}$ on the middle phenyl ring reduced potency. It is noteworthy that the unsubstituted analogues $20 \mathrm{c}$ and $20 \mathrm{~d}$ maintained good GPR142 potency and showed balanced human and mouse GPR142 potency in both FLIPR and IP assays. 
Table 2. SAR on the Left Side Imidazole Phenyl Moieties ${ }^{a}$

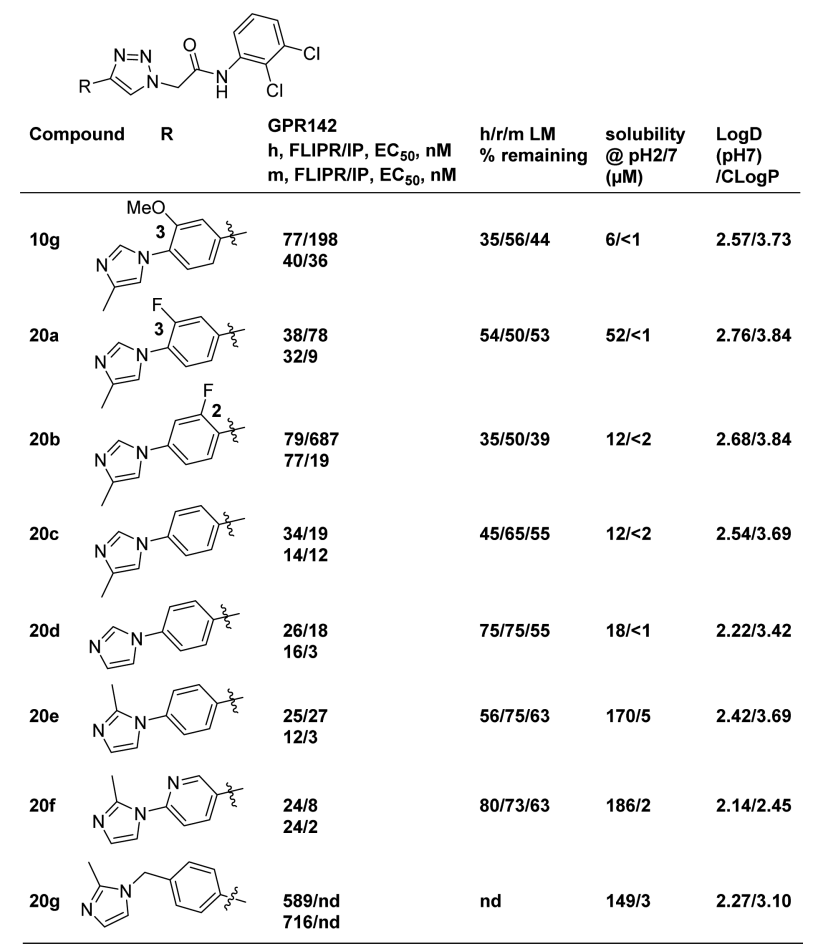

$a_{\mathrm{nd}}=$ not determined; $\mathrm{h} / \mathrm{r} / \mathrm{m} \mathrm{LM} \%$ remaining = percentage of compound remaining intact after incubation in human/rat/mouse liver microsomes at $1 \mu \mathrm{M}$ for $30 \mathrm{~min}$ at $37^{\circ} \mathrm{C}$.

Scheme 3. General Synthesis of Triazole Analogues 20a$20 \mathrm{f}^{a}$

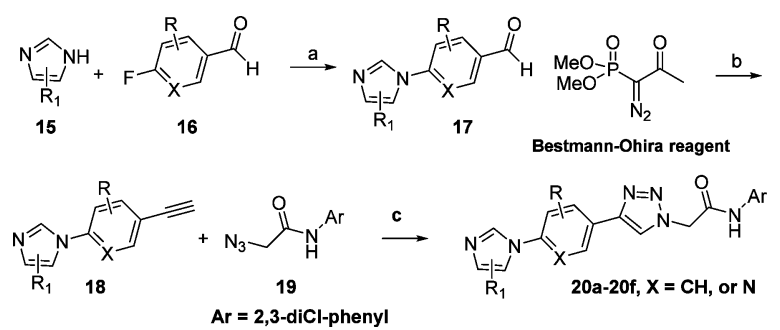

${ }^{a}$ Reagents and conditions: (a) $\mathrm{K}_{2} \mathrm{CO}_{3}$, DMF, heat; (b) $\mathrm{K}_{2} \mathrm{CO}_{3}$, $\mathrm{MeOH}$; (c) $\mathrm{CuSO}_{4}$, sodium ascorbate, $t-\mathrm{BuOH} / \mathrm{H}_{2} \mathrm{O}$.

Although the potency and metabolic stability were improved, 20c and 20d still suffered from poor solubility in phosphate buffered saline (PBS). It is well-known that poor solubility of drug candidates presents challenges during drug development. ${ }^{15}$ Improving aqueous solubility was therefore viewed as essential to identify a promising tool compound or potential drug from this series.

The Yalkowsky solubility equation ( $\log [\operatorname{solubility}(\mathrm{M})]=$ $0.5-(\log \mathrm{P})-0.01\left\{\left[\right.\right.$ melting point $\left.\left.\left.\left({ }^{\circ} \mathrm{C}\right)\right]-25\right\}\right)$ demonstrates that $\log \mathrm{P}$ and melting point are two key parameters that determine solubility. ${ }^{16}$ In addition, as summarized by Ishikawa, one effective strategy to reduce melting point is disrupting molecular planarity to decrease crystal packing. ${ }^{17}$ We hypothesized that the degree of planarity of the linear triaryl would influence crystal packing. Conformational analysis using density functional theory of compound 20d indicated that the dihedral angle between the phenyl and terminal imidazole was $38^{\circ}$, while the preferred angle was increased to $47^{\circ}$ with 2-methyl imidazole analogue $20 \mathrm{e}{ }^{18}$ To our satisfaction, 20e improved solubility in PBS dramatically at $\mathrm{pH}=2$ and modestly at $\mathrm{pH}=7$, while maintaining good GPR142 potency. It is worth noting that these dihedral angles are rather similar and that the influence on solubility may be small. The substitutions on the molecules modulate the physicochemical properties and influence the solubility and metabolic stability, which may explain the poor solubility of $10 \mathrm{~g}$, even with a dihedral angle of $44^{\circ} .{ }^{18}$ Since the $\mathrm{pH}=7$ solubility of 20e was still low, the aza analogue 20f was designed and synthesized in hope of improving solubility by reducing cLogP. Although the improvement in solubility was not significant with this modification, the GPR142 activity was well tolerated, and human liver microsome stability was further improved. To further disrupt the planarity, analogue $20 \mathrm{~g}$ with an additional methylene linker was prepared. However, this modification resulted in significant loss of GPR142 activity.

Inspired by the methyl effect in $20 \mathrm{e}$, we were also interested in whether a methyl group could be incorporated into the righthand side of the molecule (Table 3). Indeed the solubilities of

Table 3. Methylated Analogues of 20e

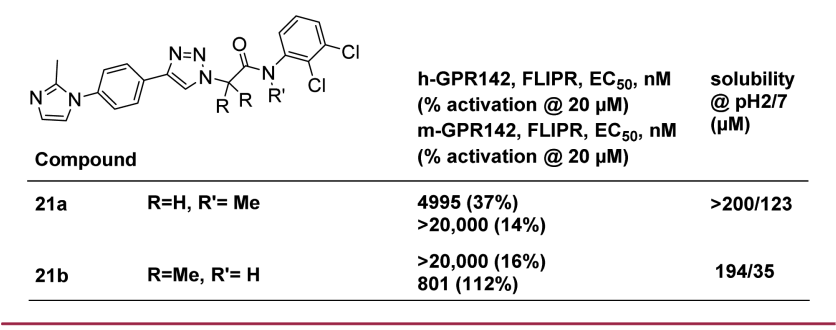

methylated analogues $\mathbf{2 1 a}$ and $\mathbf{2 1} \mathbf{b}$ were significantly improved, potentially by disrupting the crystal packing of the right-hand of the molecules. ${ }^{18}$ Unfortunately, those modifications were not tolerated for GRP142 activity.

Given their improved GPR142 potency and metabolic stability, compounds 20a, 20e, and 20f were further profiled (Table 4). These compounds exhibited acceptable selectivity profiles in CYPs 3A4 and 2D6 and in cardiac ion channels, and good permeability $\left(\mathrm{P}_{\mathrm{app}}\right)$ in LLC-PK1 cells. These compounds were also evaluated in rat pharmacokinetic studies (rat PK). All three analogues showed low to modest plasma clearance $\left(\mathrm{Cl}_{\mathrm{p}}\right)$ and good oral bioavailabilities (F\%). When corrected for plasma protein binding, however, compounds 20e and 20f

Table 4. Profile of 20a, 20e, and 20f

\begin{tabular}{|c|c|c|c|c|}
\hline & & $20 a$ & $20 e$ & $20 f$ \\
\hline \multirow[t]{2}{*}{$\mathrm{CYP}^{a} \mathrm{IC}_{50}(\mu \mathrm{M})$} & 2D6 & $>50$ & 9.4 & 18 \\
\hline & $3 \mathrm{~A} 4$ & $>50$ & 15 & 43 \\
\hline \multirow[t]{3}{*}{ ion channels ${ }^{a} \mathrm{IC}_{50}(\mu \mathrm{M})$} & Nav1.5 & $>30$ & 21 & $>30$ \\
\hline & hERG & 3.4 & 2.2 & 4.5 \\
\hline & Cav1.2 & $>30$ & 21 & $>30$ \\
\hline \multirow{6}{*}{$\begin{array}{l}\mathrm{P}_{\text {app }}{ }^{b} \\
\text { rat } \mathrm{PK}^{c} \text { (1 mpk IV, 2mpk } \\
\text { PO) }\end{array}$} & $10^{-6} \mathrm{~cm} / \mathrm{s}$ & 25 & 28 & 35 \\
\hline & $\mathrm{Cl}_{\mathrm{p}}$ & 8.7 & 13 & 13 \\
\hline & $\mathrm{Cl}_{\mathrm{u}}$ & $>8700$ & 1000 & 197 \\
\hline & $t_{1 / 2}(\mathrm{~h})$ & 0.6 & 0.9 & 0.9 \\
\hline & F (\%) & 52 & 56 & 100 \\
\hline & $\mathrm{f}_{\mathrm{u}} \%$ & $<0.1$ & 1.3 & 6.6 \\
\hline
\end{tabular}

${ }^{a}$ See ref 13 for assay protocols. ${ }^{b}$ See ref 19 for assay protocols. ${ }^{c}$ Compounds were dosed in male Sprague-Dawley rats as a solution in DMSO/PEG-200/H2O (1:4:5); $\mathrm{Cl}_{\mathrm{p}}, \mathrm{Cl}_{\mathrm{u}}$ in $\mathrm{mL} / \mathrm{min} / \mathrm{kg}$. 
exhibited lower unbound clearance $\left(\mathrm{Cl}_{\mathrm{u}}=\mathrm{Cl}_{\mathrm{p}} / \mathrm{f}_{\mathrm{u}} ; \mathrm{f}_{\mathrm{u}}=\right.$ unbound or free fraction of compound in plasma) in rats compared to 20a.

Compound 20e was selected for evaluation of its ability to potentiate glucose-stimulated insulin secretion (GSIS) ex vivo in freshly isolated mouse islets (Figure 3). ${ }^{20}$ While treatment at

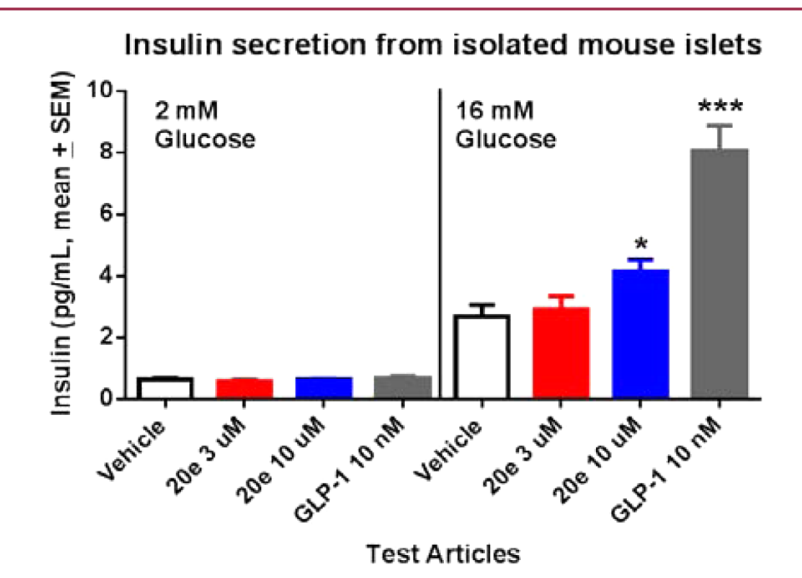

Figure 3. Compound 20e and GLP-1 showed glucose-dependent insulin secretion in isolated mouse islets. $* p<0.05$; $* * * p<0.0001$ versus vehicle (1-way ANOVA test).

low glucose concentration $(2 \mathrm{mM})$ did not show any effect on insulin secretion, at high glucose concentration (16 mM), treatment with 20e showed a modest effect on increasing insulin secretion. In the same experiment, GLP-1 showed a significant effect on enhancing insulin secretion in a glucosedependent manner as anticipated.

Compound 20e was further evaluated in vivo in lean mice in an oral glucose tolerance test (oGTT). ${ }^{20}$ In Figure 4, the black

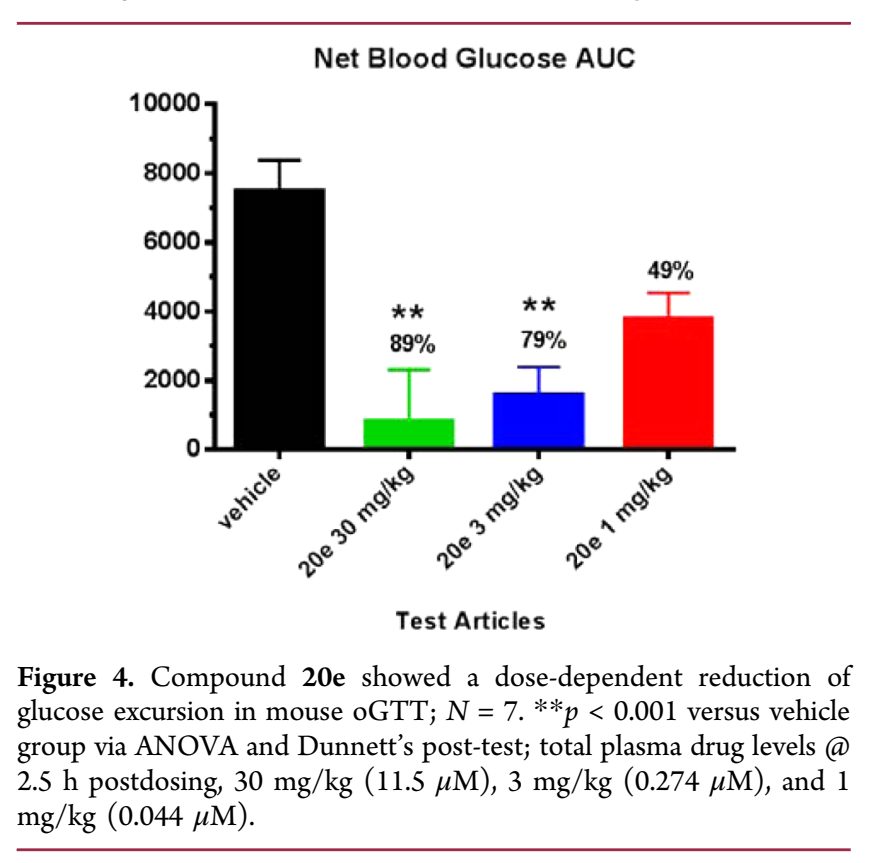

bar represents the glucose excursion after the mice were orally challenged with $5 \mathrm{~g} / \mathrm{kg}$ dextrose. Compound 20e showed a dose-dependent reduction of glucose excursion at oral doses from 1 to $30 \mathrm{mpk}$. At $30 \mathrm{mpk}, 20 \mathrm{e}$ achieved $89 \%$ glucose AUC $_{0-120 \text { min }}$ reduction $(11.5 \mu \mathrm{M}$ of total $20 \mathrm{e}$ and $149 \mathrm{nM}$ of free 20e@2.5 h postdose). To demonstrate that the observed glucose lowing effect by 20e was GPR142 mediated, 20e was tested in GPR142 $\mathrm{KO}$ mice in the same oGTT paradigm, and the compound did not reduce glucose excursion in these $\mathrm{KO}$ mice (Figure 5). This suggests that the glucose lowering effect of 20e is mediated through its GPR142 agonist activity.

Total Blood Glucose AUC

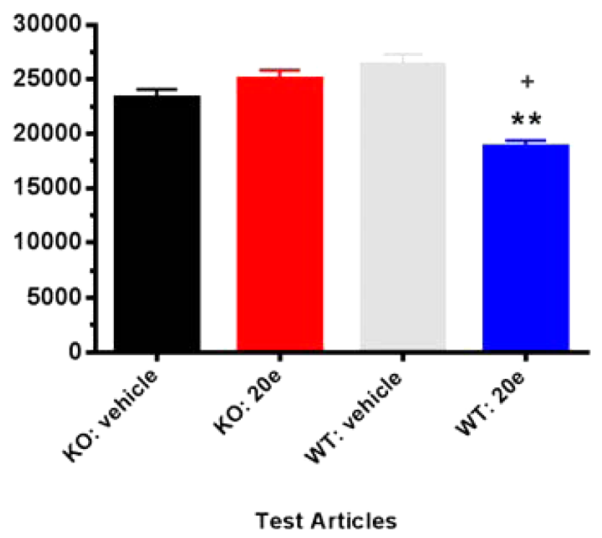

Figure 5. Glucose $\mathrm{AUC}_{0-120 \text { min }}$ following glucose challenge post 20e treatment in both wild type and GPR142 KO mice; $N=7 .^{+} p<0.01$ vs KO treatments; $* * p<0.001$ vs WT veh + dex.

In summary, a novel class of triazole GPR142 agonists was discovered from HTS. Optimization of an initial HTS hit focused on improving not only GPR142 potency, but also metabolic stability and solubility. Compound 20e demonstrated robust reduction of glucose excursion in wild-type but not in GPR142 KO mice. This mechanism-based glucose reduction provided strong evidence that GPR142 agonists could be potentially used in type 2 diabetes treatment. Further development of this class of compounds will be reported in due course.

\section{ASSOCIATED CONTENT}

\section{S Supporting Information}

The Supporting Information is available free of charge on the ACS Publications website at DOI: 10.1021/acsmedchemlett.6b00314.

Syntheses and characterization data for compound 20e, assay protocols, and computational modeling (PDF)

\section{AUTHOR INFORMATION}

\section{Corresponding Authors}

*Tel: 908-740-3355. E-mail: liangqin_guo@merck.com.

*Tel: 908-740-7326. E-mail: derun_li@merck.com.

\section{Author Contributions}

${ }^{\perp}$ Project leads.

\section{Notes}

The authors declare no competing financial interest.

\section{ACKNOWLEDGMENTS}

The authors gratefully acknowledge Dr. Eric Meade, Dr. Andrew Stamford, and Dr. Jeffrey Hale for reviewing and providing comments on this manuscript; and Jason L. Hoar for liver microsome stability studies. 


\section{REFERENCES}

(1) American Diabetes Association. Diagnosis and Classification of Diabetes Mellitus. Diabetes Care 2009, 32, S62-S67.

(2) Skyler, J. S. Diabetes Mellitus: Pathogenesis and TreatmentStrategies. J. Med. Chem. 2004, 47, 4113-4117.

(3) Weber, A. E. Dipeptidyl Peptidase IV Inhibitors for the Treatment of Diabetes. J. Med. Chem. 2004, 47, 4135-4141.

(4) Bodmer, M.; Meier, C.; Krähenbühl, S.; Jick, S. S.; Meier, C. R. Metformin, Sulfonylureas, or Other Antidiabetes Drugs and the Risk of Lactic Acidosis or Hypoglycemia, A nested case-control analysis. Diabetes Care 2008, 31 (11), 2086-2091.

(5) Suesens, U.; Hermans-Borgmeyer, I.; Urny, J.; Schaller, H. C. Characterisation and differential expression of two very closely related G-protein-coupled receptors, GPR139 and GPR142, in mouse tissue and during mouse development. Neuropharmacology 2006, 50, 512520.

(6) Wang, J.; Carrillo, J. J.; Lin, H. V. GPR142 Agonists Stimulate Glucose-Dependent Insulin Secretion via Gq-Dependent Signaling. PLoS One 2016, 11 (4), e0154452.

(7) Lizarzaburu, M.; Turcotte, S.; Du, X.; Duqutte, J.; Fu, A.; Houze, J.; Li, L.; Liu, J.; Oda, K.; Okuyama, R.; Reagan, J. D.; Yu, M.; Medina, J. C. Discovery and optimization of a novel series of GPR142 agonists for the treatment of type 2 diabetes mellitus. Bioorg. Med. Chem. Lett. 2012, 22, 5942-5947.

(8) Du, X.; Kim, Y.-J.; Lai, S.; Chen, X.; Lizarzaburu, M.; Turcotte, S.; Oda, K.; Okuyama, R.; Nara, F.; Murakoshi, M.; Fu, A.; Reagan, J.; Liu, Q.; Zhang, Y.; Motani, A.; Fan, P.; Xiong, Y.; Shen, W.; Li, L.; Houze, J.; Medina, J. C. Phenylalanine derivatives as GPR142 agonists for the treatment of Type II diabetes. Bioorg. Med. Chem. Lett. 2012, 22, 6218-6223.

(9) Yu, M.; Lizarzaburu, M.; Motani, A.; Fu, Z.; Du, X.; Liu, J.; Jiao, X.; Lai, S.; Fan, P.; Fu, A.; Liu, Q.; Murakoshi, M.; Nara, F.; Oda, K.; Okuyama, R.; Reagan, J. D.; Watanabe, N.; Yamzaki, M.; Xiong, Y.; Zhang, Y.; Zhuang, R.; Lin, D. C.; Houze, J. B.; Medina, J. C.; Li, L. Aminopyrazole-Phenylalanine Based GPR142 Agonists: Discovery of Tool Compound and in Vivo Efficacy Studies. ACS Med. Chem. Lett. 2013, 4, 829-834.

(10) Toda, N.; Hao, X.; Ogawa, Y.; Oda, K.; Yu, M.; Fu, Z.; Chen, Y.; Kim, Y.; Lizarzaburu, M.; Lively, S.; Lawlis, S.; Murakoshi, M.; Nara, F.; Watanabe, N.; Reagan, J. D.; Tian, H.; Fu, A.; Motani, A.; Liu, Q.; Lin, Y.-J.; Zhuang, R.; Xiong, Y.; Fan, P.; Medina, J.; Li, L.; Izumi, M.; Okuyama, R; Shibuya, S. Potent and Orally Bioavailable GPR142 Agonists as Novel Insulin Secretagogues for the Treatment of Type 2 Diabetes. ACS Med. Chem. Lett. 2013, 4, 790-794.

(11) Wilson, J. E.; Kurukulasuriya, R.; Sinz, C.; Lombardo, M.; Bender, K.; Parker, D.; Sherer, E. C.; Costa, M.; Dingley, K.; Li, X.; Mitelman, S.; Tong, S.; Bugianesi, R.; Ehrhardt, A.; Priest, B.; Ratliff, K.; Ujjainwalla, F.; Nargund, R.; Hagmann, W. K.; Edmondson, S. Discovery and development of benzo-[1,2,4]-triazolo-[1,4]-oxazepine GPR142 agonists for the treatment of diabetes. Bioorg. Med. Chem. Lett. 2016, 26, 2947-2951.

(12) Compound $\mathbf{4}$ originated from a class of $\gamma$-secretase modulators: Fischer, C.; Zultanski, S. L.; Zhou, H.; Methot, J. L.; Shah, S.; Nuthall, H.; Hughes, B. L.; Smotrov, N.; Hill, A.; Szewczak, A. A.; Moxham, C. M.; Bays, N.; Middleton, R. E.; Munoz, B.; Shearman, M. S. Triazoloamides as potent $\gamma$-secretase modulators with reduced hERG liability. Bioorg. Med. Chem. Lett. 2012, 22, 3140-3146.

(13) Protocols for GPR142 FLIPR assay and GPR142 IP inositol phosphate (IP) accumulation assay can be found in the Supporting Information.

(14) For details on the glucose tolerance test models in mice, please see: Tan, C. P.; Feng, Y.; Zhou, Y.-P.; Eiermann, G. J.; Petrov, A.; Zhou, C.; Lin, S.; Salituro, G.; Meinke, P.; Mosley, R.; Akiyama, T. E.; Einstein, M.; Kumar, S.; Berger, J. P.; Mills, S. G.; Thornberry, N. A.; Yang, L.; Howard, A. D. Selective small-molecule agonists of G protein-coupled receptor 40 promote glucose-dependent insulin secretion and reduce blood glucose in mice. Diabetes 2008, 57 (8), 2211-2219.
(15) Stegemann, S.; Leveiller, F.; Franchi, D.; de Jong, H.; Lindén, H. When Poor Solubility Becomes an Issue: From Early Stage to Proof of Concept. Eur. J. Pharm. Sci. 2007, 31, 249-261.

(16) Jain, N.; Yalkowsky, S. H. Estimation of the Aqueous SolubilityI: Application to Organic Nonelectrolytes. J. Pharm. Sci. 2001, 90, 234252.

(17) Ishikawa, M.; Hashimoto, Y. Improvement in aqueous solubility in small molecule drug discovery programs by disruption of molecular planarity and symmetry. J. Med. Chem. 2011, 54, 1539-1554.

(18) Details of the synthesis of 20e and computational modeling can be found in the Supporting Information.

(19) He, H.; Lyons, K.; Shen, X.; Yao, Z.; Bleasby, K.; Chan, G.; Hafey, M.; Li, X.; Xu, S.; Salituro, G. M.; Cohen, L. H.; Tang, W. Utility of unbound plasma drug levels and p-glycoprotein transport data in prediction of central nervous system exposure. Xenobiotica 2009, 39, 687-693.

(20) For details on oGTT and GSIS study models in mice, please see the Supporting Information, ref 14 , and the following references: (a) Shah, S.; He, S.; Guo, L.; Truong, Q.; Qi, H.; Du, W.; Lai, Z.; Liu, J.; Jian, T.; Hong, Q.; Dobbelaar, P.; Ye, Z.; Sherer, E.; Feng, Z.; Yu, Y.; Wong, F.; Samuel, K.; Madiera, M.; Karanam, B. V.; Reddy, V. B.; Mitelman, S.; Tong, S. X.; Chicchi, G. G.; Tsao, K.-L.; Trusca, D.; Feng, Y.; Wu, M.; Shao, Q.; Trujillo, M. E.; Eiermann, G. J.; Li, C.; Pachanski, M.; Fernandez, G.; Nelson, D.; Bunting, P.; Morissette, P.; Morissette, P.; Volksdorf, S.; Kerr, J.; Zhang, B. B.; Howard, A. D.; Zhou, Y.-P.; Pasternak, A.; Nargund, R. P.; Hagmann, W. K. Discovery of MK-1421, a potent, selective sstr3 antagonist, as a development candidate for type 2 diabetes. ACS Med. Chem. Lett. 2015, 6, 513-517. (b) Lacy, P. E.; Kostianovsky, M. Method for the isolation of intact islet of Langerhans from the rat pancreas. Diabetes 1967, 16, 35-39. 